\title{
DIAZOXIDE-INDUCED HYPERGLYCEMIA IN RATS IS REGULATED BY MODULATION OF CALCIUM RECEPTOR ACTIVITY
}

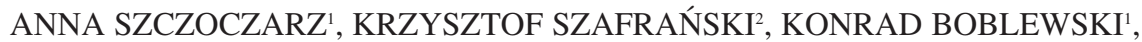 \\ ARTUR LEHMANN ${ }^{1}$, JAROSŁAW SŁAWIŃSKI ${ }^{2}$, BARBARA LEWKO ${ }^{1}$ \\ and APOLONIA RYBCZYŃSKA ${ }^{1 *}$ \\ ${ }^{1}$ Department of Pathophysiology, \\ ${ }^{2}$ Department of Organic Chemistry, \\ Faculty of Pharmacy, Medical University of Gdansk, Poland
}

\begin{abstract}
The mechanism of insulin secretion by pancreatic $\beta$-cells includes closure of the $\mathrm{K}_{\mathrm{ATP}}$ channels, depolarization of plasma membrane and stimulation of the $\mathrm{Ca}^{2+}$ influx. The increase of intracellular $\mathrm{Ca}^{2+}$ may also be induced by activation of the phospholipase C (PLC)- coupled calcium receptor (CaR) that is present in pancreatic islets. Diazoxide increases blood glucose concentration by inhibiting pancreatic insulin secretion. The mechanism of action of diazoxide involves opening of $\mathrm{K}_{\mathrm{ATP}}$ channels, cell membrane hyperpolarization, and inhibition of $\mathrm{Ca}^{2+}$ influx into the cells. The present study was designated to determine the in vivo effects of CaR activation by R-568 and CaR inhibition by NPS 2143 on plasma glucose and insulin levels in the presence of diazoxide. Wistar rats, after $14 \mathrm{~h}$ fasting, were anesthetized with inactin and loaded ip with diazoxide 40 $\mathrm{mg} / \mathrm{kg}$ b.w.. R-568 and NPS2143 were given $i v$ in doses 1 and $2 \mathrm{mg} / \mathrm{kg}$ b.w., respectively. Blood glucose, $\mathrm{Ca}^{2+}$ and insulin levels were determined in selected time points while blood pressure was continuously monitored during the experiment. Diazoxide significantly increased blood glucose level in all tested groups. However, as compared to the rats receiving diazoxide alone, glucose concentration was lower in diazoxide/R-568 group, whereas markedly higher in diazoxide/NPS2143 group. Adversely, insulin level was higher in diazoxide/R-568 and lower in diazoxide /NPS2143 rats, than in animals given diazoxide alone. These results highlight the importance of CaR activity in diazoxide-induced hyperglycemia and hypoinsulinemia.
\end{abstract}

Keywords: NPS2143, R-568, $\mathrm{K}_{\mathrm{ATP}}$ channel opener, calcium receptor, hyperglycemia

The mechanism of insulin secretion by pancreatic $\beta$-cells induced by increased plasma glucose includes the rise in cytoplasmic $\mathrm{Ca}^{2+}$ concentration resulting from the increased ATP/ADP ratio, closure of the ATP-regulated $\mathrm{K}^{+}$channels, depolarization of the plasma membrane and stimulation of the $\mathrm{Ca}^{2+}$ influx (1). Subsequently, elevated intracellular $\mathrm{Ca}^{2+}$ increases the rate of exocytosis of insulin (2).

Moreover, it was observed that the opening of $\mathrm{K}_{\mathrm{ATP}}$ channels by diazoxide inhibited insulin release from pancreatic $\beta$-cells and caused hyperglycemia $(3,4)$. Diazoxide (Proglicem) given orally is clinically used to treat symptomatic hypoglycemia (5). Intravenously administered diazoxide (Hyperstat) is also indicated as a peripheral vasodilator in the emergency reduction of blood pressure (6). The mechanism of diazoxide clinical action is related to the opening of pancreatic and smooth muscle $\mathrm{K}_{\mathrm{ATP}}$ channels, membrane hyperpolarization, a decrease of intracellular $\mathrm{Ca}^{2+}$ concentration as a result of inhibition of $\mathrm{Ca}^{2+}$ influx, and reduction of insulin release from pancreatic $\beta$-cells $(3,7)$.

The calcium receptor $(\mathrm{CaR})$ belongs to the family of $\mathrm{G}$ protein-coupled and phospholipase $\mathrm{C}$ (PLC) activated receptors, both in rats $(8,9)$ and in humans (10). The CaR was found for the first time on the surface of parathyroid cells and is known to play a key role in the regulation of the plasma calcium concentration (11). Moreover, activators of CaR (Cinacalcet, Mimpara) are clinically used to regulate PTH secretion and plasma calcium concentration in primary and secondary hyperparathyroidism (12, 13). In addition, $\mathrm{CaR}$ expression has been found in many other cells and tissues that are not directly involved in the systemic regulation of plasma $\mathrm{Ca}^{2+}$, e.g. in fibroblasts (14), neuronal cells (15), endothelial cells (16). Recently, the presence of the calcium receptors in rat pancreatic $\beta$ cells has also been

\footnotetext{
* Corresponding author: e-mail: apolonia.rybczynska@gumed.edu.pl
} 
reported $(8,9)$. Activation of the $\mathrm{CaR}$, and subsequent activation of PLC, increase cytoplasmic $\mathrm{Ca}^{2+}$ concentration due to the liberation of $\mathrm{Ca}^{2+}$ from intracellular storages (11). Therefore, mediated by increased intracellular $\mathrm{Ca}^{2+}$ concentration rise in insulin secretion may result from both high plasma glucose level and $\mathrm{CaR}$ activation. The $\mathrm{CaR}$ may be activated by extracellular $\mathrm{Ca}^{2+}$ as well as by other factors, e.g. by inorganic and organic polycations (17). Calcimimetics, such as phenylalkylamine R-568, activate CaR allosterically, and increase the affinity of the receptor for extracellular $\mathrm{Ca}^{2+}(18)$. Experiments performed on pancreatic $\beta$-cells in vitro show that activation of calcium receptor by calcimimetic R-568 increases insulin secretion, which is due to enhanced release of $\mathrm{Ca}^{2+}$ from intracellular storages and increased cytoplasmic $\mathrm{Ca}^{2+}$ concentration (19). Our recently published in vivo experiments confirmed the hypothesis that modulation of CaR activity may also participate in the mechanisms that mediate insulin secretion since the administration of R-568, an agonist of $\mathrm{CaR}$ increased insulin level in rats whereas CaR antagonist, NPS2143, had the opposite effect (20). Furthermore, calcium channel blockade by verapamil may prevent changes in blood glucose and insulininduced by $\mathrm{CaR}$ activation in rats (21).

The present study was designed to examine the in vivo effects of $\mathrm{CaR}$ activation by $\mathrm{R}-568$ and $\mathrm{CaR}$ inhibition by NPS2143 on blood glucose and insulin concentrations in the presence of diazoxide, a $\mathrm{K}_{\text {ATP }}$ channel opener.

\section{EXPERIMENTAL}

\section{Animals and surgical procedures}

Male Wistar rats weighing 250 to $280 \mathrm{~g}$ were purchased from the Animal House of the Medical University of Gdańsk (Gdańsk, Poland). The rats were kept at constant room temperature $\left(20^{\circ} \mathrm{C}\right)$ and humidity (70\%), under the 12-h dark/light cycles. All experiments were approved by the Local Ethical Committee on Animal Experiments (Bydgoszcz, Poland), Decision number 42/2019. The animals were fed commercial rodent chow (Labofeed-B, Warszawa, Poland) and provided with tap water ad libitum. Before the experiment, the rats have fasted for $14 \mathrm{~h}$ (starting at 9 p.m.). On the experiment day, the rats were anesthetized intraperitoneally with inactin at the dose of $100 \mathrm{mg} / \mathrm{kg}$ b.w.. The animals were placed on a heated table and their body temperature was maintained at 36 to $37^{\circ} \mathrm{C}$. Tracheostomy was performed, and catheters were inserted: in the jugular vein for infusion, in the carotid artery for blood sampling and the monitoring of the mean arterial blood pressure
(MAP), and in the bladder for free diuresis. After all surgical procedures, a $30 \mathrm{~min}$ recovery period was allowed to establish a steady-state. Over the whole experiment, the rats were infused with isotonic saline supplemented with heparin $(1 \mathrm{U} / \mathrm{mL}$ of the solution) at the rate of $1.2 \mathrm{~mL} / \mathrm{h}$.

\section{Experimental design}

The effect of R-568 or NPS 2143 on MAP and blood glucose, $\mathrm{Ca}^{2+}$ and insulin levels in diazoxidetreated rats

For experiments, rats were divided into four groups: those receiving diazoxide and R-568 $(n=5)$ or NPS $2143(n=5)$, those receiving diazoxide alone $(n=5)$, and the control group $(n=6)$. After the recovery period, diazoxide at the dose $40 \mathrm{mg} / \mathrm{kg}$ b.w., dissolved in dimethylsulfoxide (DMSO), was given intraperitoneally. $10 \mathrm{~min}$ later, R-568 at the dose $1 \mathrm{mg} / \mathrm{kg}$ b.w. or NPS 2143 at the dose of $2 \mathrm{mg} / \mathrm{kg}$ b.w., dissolved in $15 \%$ cyclodextrin, were administered as $100 \mu \mathrm{L}$ boluses through the venous catheter. The time of R-568 or NPS 2143 administration was set as time 0 of the experiment. Glucose, measurements were performed before the NPS 2143 or R-568 injection and 30, 60, 90, 120, 150,180, 210, and $240 \mathrm{~min}$ thereafter. Blood collections for insulin and MAP measurements were performed 10 min prior and 60, 150 and 240 min after administration of the compounds. $\mathrm{Ca}^{2+}$ concentration was determined at $-20,60,120$, and $180 \mathrm{~min}$ of the experiment.

In the diazoxide group, the animals were infused with $100 \mu \mathrm{L}$ of $15 \%$ cyclodextrin $i v$ instead of R-568 or NPS 2143. Otherwise, the experimental protocol was identical to that described above.

In the control group, the animals were injected with $500 \mu \mathrm{L}$ of DMSO ip instead of diazoxide and with $100 \mu \mathrm{L}$ of $15 \%$ cyclodextrin $i v$ instead of R-568 or NPS 2143. Otherwise, the experimental protocol was identical to that described above.

Glucose, $\mathrm{Ca}^{2+}$, insulin, and blood pressure meas-
urements
Blood glucose was measured using a glucometer (ACCU-CHECK Active, model: GC ACCUCHEK, Roche, Mannheim, Germany). $\mathrm{Ca}^{2+}$ concentration in blood was measured using the 9180 Electrolyte Analyser, Roche Diagnostic GmbH, Mannheim, Germany. Insulin was determined in 10-25 $\mu \mathrm{L}$ plasma using an enzyme-linked immunosorbent assay: DRG ultrasensitive Rat Insulin ELISA (DRG International, Inc., Springfield, NJ, USA), according to the manufacturer's instruction; samples were analyzed in duplicate. Arterial blood 


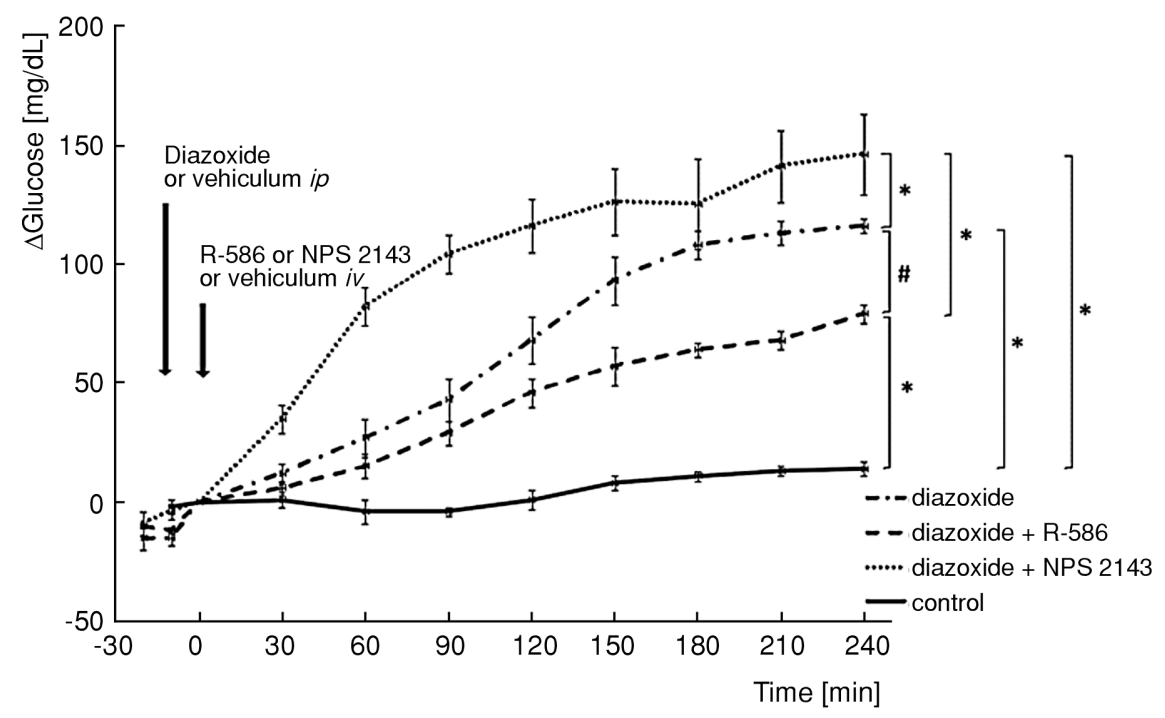

Figure 1. Effects of iv R-568 and NPS2143 administration on the diazoxide-dependent changes in blood glucose level. $\Delta$ glucose was calculated as the difference between sequential measurements of blood glucose concentrations during experiment and concentration at the time 0 (control $n=6$; diazoxide $n=5$; diazoxide/R-568 $n=5$; diazoxide/2143 $n=5$ ). Statistical comparisons were performed using ANOVA with repeated measurements and the Fisher test; ${ }^{*} \mathrm{p}<0.001, \# \mathrm{p}<0.009$.

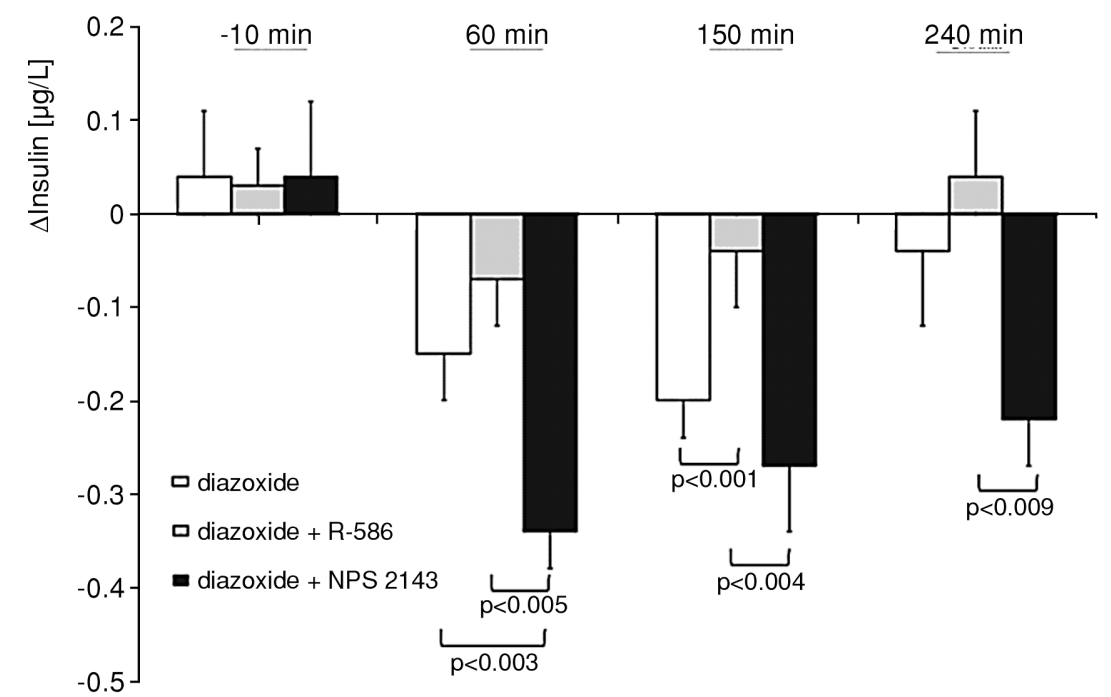

Figure 2. Effects of the iv R-568, and NPS2143 administration on the diazoxide-dependent changes in blood insulin level. $\Delta$ insulin was calculated as the difference between sequential measurements of plasma insulin concentration during the experiment and the mean value of insulin concentration in the control group at the selected time points of the experiment (diazoxide $\mathrm{n}=5$; diazoxide/R-568 $\mathrm{n}=5$; diazoxide/2143 $\mathrm{n}=5$ ). Statistical comparisons were performed using ANOVA with repeated measurements and the Fisher test.

pressure was monitored directly using BIOPAC by Systems Inc., Model MP 100 (Goleta, CA, USA).

\section{Drugs and chemicals}

The following chemicals and drugs were used: Inactin hydrate CIIIN, Sigma, St. Louis, MO, USA; isotonic saline, Fresenius Kabi, Warszawa, Poland; Heparinum, POLFA, Warszawa, Poland. NPS 2143 and R-568 were purchased from TOCRIS, Tocris Bioscience, Bristol, UK. All other chemicals were purchased from Sigma-Aldrich, Poznań, Poland.

\section{Statistical calculations}

All values are presented as the mean \pm SE. Comparisons were performed using ANOVA with repeated measurements followed by the Fisher test 
and Student's $t$-test as appropriate. The significance level was designated as $\mathrm{p}<0.05$.

\section{RESULTS}

Initial glucose concentrations were $82 \pm 4,85 \pm$ $4,81 \pm 3$, and $90 \pm 2 \mathrm{mg} / \mathrm{dL}$ in diazoxide, diazoxide/R-568, diazoxide/NPS2143, and control groups, respectively. The effect of diazoxide, diazoxide/R568 , and diazoxide/NPS2143 on blood glucose level is shown in Figure 1. The blood glucose concentration is presented as the difference between sequential measurements during the experiment and the concentration at the time 0 of the experiment. In all groups of animals, a significant increase in glucose level was observed in comparison to the control $(\mathrm{p}<0.001)$. However, glucose concentration was markedly lower in diazoxide/R-568 rats than in rats receiving diazoxide alone $(p<0.001)$. Moreover, the glucose level was higher in diazoxide/NPS2143 group than in the diazoxide group $(\mathrm{p}<0.001)$. Furthermore, a significantly greater increase in glucose concentration was observed in diazoxide/ NPS2143 animals as compared to diazoxide/R-568 group ( $\mathrm{p}<0.001)$.

Figure 2 summarizes changes in plasma insulin levels in rats. The changes in insulin concentration are presented as the difference between sequential measurements of insulin during the experiment and the mean value of insulin concentration in the control group at the selected time point of the experiment. In diazoxide/R-568 group, insulin level was higher vs diazoxide group at $150 \mathrm{~min}$ of the experiment $(\mathrm{p}<0.01)$, while in diazoxide/NPS2143 group insulin level decreased at $60 \mathrm{~min}$ of the experiment ( $\mathrm{p}<0.003$ ). Moreover, at 60 and $150 \mathrm{~min}$ of the experiment more pronounced decrease in insulin concentration was observed in diazoxide/NPS2143 animals than in the diazoxide/R-568 group, $\mathrm{p}<$ 0.008 , and $\mathrm{p}<0.004$, respectively.

The $\mathrm{Ca}^{2+}$ levels determined during the experiment (Table 1) indicated a decrease of blood $\mathrm{Ca}^{2+}$ concentration in diazoxide/R-568 and rise of $\mathrm{Ca}^{2+}$ in diazoxide/NPS2143 as compared to the control group and initial period. Moreover, in diazoxide animals, no significant changes in blood $\mathrm{Ca}^{2+}$ concentration were observed.

In all groups of rats treated with diazoxide, the MAP decreased in comparison to the control group and to the initial period (Table 2).

\section{DISCUSSION}

Elevated plasma glucose concentration triggers the pancreatic $\beta$ cells to secrete insulin. Upon increased intracellular ATP/ADP ratio, the ATPregulated $\mathrm{K}^{+}$channels open and the plasma membrane depolarizes. In consequence, the voltagedependent $\mathrm{Ca}^{2+}$ channels open and free cytoplasmic $\mathrm{Ca}^{2+}$ rises, which, in multiple ways increases the rate of exocytosis of insulin from the insulin storing secretory granules (1). Extracellular $\mathrm{Ca}^{2+}$ in turn activates $\mathrm{CaR}$, the receptor coupled to phospholipase C. Stimulated this way PLC increases the cytoplasmic $\mathrm{Ca}^{2+}$ level by releasing $\mathrm{Ca}^{2+}$ from intracellular stores via diacylglycerol and phosphatidylinositol bisphosphate metabolic pathways (22). Thus, it seems plausible that the secretion of insulin triggered by elevated intracellular $\mathrm{Ca}^{2+}$ may result from both high plasma glucose level and activation of CaR.

Activation by agonist R-467 of the $\mathrm{CaR}$ in a mouse-derived $\beta \mathrm{HC} 9$ cell line and in pancreatic islets from $\mathrm{C} 57 \mathrm{BL} / 6$ mice revealed increased insulin secretion in the presence of a stimulatory concentration of glucose (23). Moreover, in another in vitro study in which R-568 was used as the CaR activating agent, transient stimulation of insulin secretion from human pancreatic $\beta$-cells was observed (19). Recently published results of our experiments have shown for the first time that in the in vivo conditions activation of CaR by calcimimetic R-568 was effective in augmenting the plasma insulin concentration and decreas-

Table 1. Effects of R-568 and NPS 2143 administration on blood $\mathrm{Ca}^{2+}$ concentration in the presence of diazoxide in rats.

\begin{tabular}{|c|c|c|c|c|}
\hline \multirow{2}{*}{ Time $[\mathrm{min}]$} & \multicolumn{4}{|c|}{$\mathrm{Ca}^{2+}[\mathrm{mmol} / \mathrm{L}]$} \\
\cline { 2 - 5 } & $\begin{array}{c}\text { Control } \\
(\mathrm{n}=5)\end{array}$ & $\begin{array}{c}\text { Diazoxide } \\
(\mathrm{n}=5)\end{array}$ & $\begin{array}{c}\text { Diazoxide/R-568 } \\
(\mathrm{n}=5)\end{array}$ & $\begin{array}{c}\text { Diazoxide/NPS } 2143 \\
(\mathrm{n}=5)\end{array}$ \\
\hline-20 & $1.36 \pm 0.01$ & $1.36 \pm 0.02$ & $1.35 \pm 0.01$ & $1.38 \pm 0.01$ \\
\hline 60 & $1.36 \pm 0.01$ & $1.37 \pm 0.01$ & $1.16 \pm 0.01^{\text {*** }}$ & $1.43 \pm 0.01^{\text {*** }}$ \\
\hline 120 & $1.37 \pm 0.01$ & $1.34 \pm 0.02$ & $1.20 \pm 0.01^{\text {** }}$ & $1.42 \pm 0.01^{\text {** }}$ \\
\hline 180 & $1.37 \pm 0.02$ & $1.31 \pm 0.02$ & $1.26 \pm 0.01^{\text {*** }}$ & $1.36 \pm 0.02$ \\
\hline
\end{tabular}

Data are presented as the means $\pm \mathrm{SE}$; $\mathrm{n}$, number of animals. Comparisons were made using Student's t-test: ${ }^{*} \mathrm{p}<0.05$ vs initial period, ${ }^{*}$ $\mathrm{p}<0.05$ vs control group. 
Table 2. Effects of R-568 and NPS 2143 administration on mean arterial pressure in the presence of diazoxide in rats.

\begin{tabular}{|c|c|c|c|c|}
\hline \multirow{2}{*}{ Time $[\mathrm{min}]$} & \multicolumn{4}{|c|}{ MAP [mmH] } \\
\cline { 2 - 5 } & $\begin{array}{c}\text { Control } \\
(\mathrm{n}=5)\end{array}$ & $\begin{array}{c}\text { Diazoxide } \\
(\mathrm{n}=5)\end{array}$ & $\begin{array}{c}\text { Diazoxide/R-568 } \\
(\mathrm{n}=5)\end{array}$ & $\begin{array}{c}\text { Diazoxide/NPS } 2143 \\
(\mathrm{n}=5)\end{array}$ \\
\hline-10 & $117 \pm 4$ & $116 \pm 2$ & $114 \pm 2$ & $117 \pm 4$ \\
\hline 60 & $108 \pm 4$ & $85 \pm 3^{* *}$ & $89 \pm 2^{* *}$ & $87 \pm 7^{* *}$ \\
\hline 150 & $104 \pm 4^{*}$ & $79 \pm 5^{* *}$ & $77 \pm 2^{* *}$ & $90 \pm 6^{*}$ \\
\hline 240 & $103 \pm 5^{*}$ & $82 \pm 7^{* *}$ & $80 \pm 3^{* *}$ & $84 \pm 5^{* *}$ \\
\hline
\end{tabular}

MAP, mean arterial blood pressure; $n$, number of animals. Data are presented as means \pm SE. Comparisons were made using Student's ttest: $* \mathrm{p}<0.05$ vs initial period, \# $\mathrm{p}<0.05$ vs control group.

ing blood glucose concentrations. Furthermore, we indicated that inhibition of the $\mathrm{CaR}$ by calcilytic NPS2143 provoked the opposite effects (20).

Used in our experiments diazoxide increases blood glucose concentration by inhibiting pancreatic insulin secretion. The mechanism of inhibition of insulin secretion by diazoxide involves opening of $\mathrm{K}_{\mathrm{ATP}}$ channels, cell membrane hyperpolarization, and inhibition of $\mathrm{Ca}^{2+}$ influx into the cells, which results in a decrease of intracellular $\mathrm{Ca}^{2+}$ concentration $(3,4)$.

Results of the present study clearly indicate for the first time that in the in vivo conditions, activation of calcium receptor $(\mathrm{CaR})$ in rats decreases hyperglycemia induced by diazoxide, and conversely, inhibition of the receptor increases blood glucose concentration. The changes in glucose levels were accompanied by respective, inverse changes in blood insulin levels.

To provide stable baseline measurements of plasma glucose in rats, we used in our experiments the generally applied procedure of overnight fasting (24). The opening of the potassium channels in response to diazoxide significantly increased the blood glucose levels in all experimental groups. Yet, activation of CaR by R-568 in the diazoxide-treated rats markedly reduced blood glucose, as compared to the animals receiving diazoxide alone $(\mathrm{p}<0.001)$. On the other hand, in rats given diazoxide, inhibition of CaR by NPS2143 significantly increased blood glucose in comparison to rats given diazoxide alone $(\mathrm{p}<0.001)$. As a consequence, there was also a marked difference in blood glucose concentrations between diazoxide/R-568 and diazoxide/NPS2143 groups $(\mathrm{p}<0.001)$. These results clearly show the relevance of $\mathrm{CaR}$ activity during hyperglycemia induced by the diazoxide-dependent opening of potassium channels.

The observed blood glucose changes were accompanied by summarized in Figure 2 alterations in plasma insulin levels. In diazoxide/ NPS2143 and
diazoxide/R-568 groups, changes in insulin concentrations vs diazoxide group corresponded to the above-described changes in glucose concentrations, and significance $(\mathrm{p}<0.003)$ and $(\mathrm{p}<0.01)$ was observed at 60 and $150 \mathrm{~min}$ of the experiment. Also, differences between decreases of insulin levels in diazoxide/NPS2143 and diazoxide/R-568 groups were statistically significant at 60 and $150 \mathrm{~min}$ of the experiment $(\mathrm{p}<0.008$ and $\mathrm{p}<0.004$ respectively). Taken together, these results prove the contribution of $\mathrm{CaR}$ in diazoxide induced hyperglycemia and hypoinsulinemia.

In our experiments, we applied calcimimetic R-568, the agonist of CaR, and calcilytic NPS2143, the antagonist of CaR. Both compounds were previously used by other authors (17 Brown and MacLeod, 2001) and by us $(25,26)$ and are known to modify the activity of $\mathrm{Ca}$ receptor and to influence blood calcium concentration. The determined during the experiment $\mathrm{Ca}^{2+}$ levels (Table 1) confirmed the expected decrease of blood $\mathrm{Ca}^{2+}$ concentration in diazoxide/R-568 and rise of $\mathrm{Ca}^{2+}$ in diazoxide/NPS2143 groups, which corroborates the adequacy of used by us compounds doses. Moreover, the results showed that diazoxide administration did not induce significant changes in blood $\mathrm{Ca}^{2+}$ concentrations in comparison to the control group, as well as to the initial period. Since the in vitro experiments demonstrated that increasing $\mathrm{Ca}^{2+}$ concentrations $(0.2-1.2 \mathrm{mM})$ had no effect on insulin secretion by human $\beta$ cells (19), the in vivo changes of $\mathrm{Ca}^{2+}$ concentration within physiological values per se seem unlikely to influence this process.

Diazoxide, the $\mathrm{K}_{\text {ATP }}$ channel opener, originally described as exhibiting vasodilatory activity when given orally in hypertensive dogs (27) was also clinically used to treat severe hypertension in hospitalized adults and children (6). Therefore in our study, the blood pressure was monitored during the experiment. As expected, in all groups of diazoxide-treated rats, the MAP decreased in comparison to the 
control group and the initial period, although the values were within the normal ranges (Table 2).

In summary, the present study shows that in the in vivo conditions activation by R-568 of calcium receptor reduces diazoxide-induced hyperglycemia while CaR inhibition, by NPS2143, augments the $\mathrm{K}_{\text {ATP }}$ channel-dependent effect. Moreover, in diazoxide-induced hypoinsulinemia, the modifications of glucose concentration were accompanied by blood insulin rise after $\mathrm{CaR}$ activation and insulin reduction when $\mathrm{CaR}$ was inhibited. Our results may be helpful in the pharmacotherapy of patients with diabetes and primary or secondary hyperparathyroidism.

\section{Conflict of interests}

The authors declare that the research was conducted in the absence of any commercial or financial relationships that could be construed as a potential conflict of interest.

\section{Acknowledgments}

The study was supported with the Funds for Statutory Activity of the Medical University of Gdańsk (ST-54) and by the project POWR.03.02. 00-00-I035/16-00 co-financed by the European Union through the European Social Fund under the Operational Programme Knowledge Education Development 2014-2020.

\section{REFERENCES}

1. Ahren B.: Nat. Rev. Drug Discov. 8, 369 (2009).

2. Satin L.S.: Endocrin. J. 13, 251 (2000).

3. Henquin J.C., Meissner H.P.: Biochem. Pharmacol. 31, 1407 (1982).

4. Okun R., Wilson W.R., Gelfand M.D.: J. Chronic. Dis. 17, 31 (1964).

5. Hussain K., Aynsley-Green A., Stanley CA.: Pediatr. Endocrinol. Rev. 2, 163 (2004).

6. Coetzee W.A.: Pharmacol. Ther. 140, 167 (2013).

7. Trube G., Rorsman P., Ohno-Shosaku T.: Eur. J. Physiol. 407, 493-499. (1986).

8. Bruce J.I., Yang X., Ferguson C.J., Elliott A.C., Steward M.C., et al.: J. Biol. Chem. 274, 20561 (1999).
9. Squires P.E.: J. Endocrinol. 164, 173 (2000).

10. Kato M., Doi R., Imamura M., Furutani M., Hosotani R., Shimada Y.: Surgery 122, 1203 (1997).

11. Brown E.M.: Physiol. Rev. 71, 371 (1991).

12. Manaka K., Sato J., Kinoshita Y., Ito N., Fujita M., et al.: Endocr. J. 66, 683 (2019).

13. Moe S.M., Cunningham J., Bommer J., Adler S., Rosansky S.J., et al.: Nephrol. Dial. Transplant. 20, 2186 (2005).

14. McNeil S.E., Hobson S.A., Nipper V., Rodland K.D.: J. Biol. Chem. 273, 1114 (1998).

15. Chattopadhyay N., Ye C., Kifor O., Yamaguchi T., Vassilev P.M., et al.: Glia 24, 449 (1998).

16. Cheng I., Klingensmith M.K., Chattopadhyay N., Butters R.R., Soybel D.I., Brown E.M.: J. Clin. Endocrinol. Met. 83, 703 (1998).

17. Brown E.M., MacLeod R.J.: Physiol. Rev. 81, 239 (2001).

18. Nemeth E.F., Steffey M.E., Hammerland L.G., Hung B.C., Van Wagenen B.C., et al.: Proc. Natl. Acad. Sci. USA 95, 4040 ( 1998).

19. Gray E., Muller D., Squires P.E., Asare-Anane H., Huang G.C., et al.: J. Endocrinol. 190,703 (2006).

20. Rybczyńska A., Marchwińska A., Dyś A., Boblewski K., Lehmann A., Lewko B.: Pharmacol. Rep. 69, 709 (2017).

21. Szczoczarz A., Marchwińska A., Dyś A., Boblewski K., Lehmann A., et al.: Pharmacol. Rep. 71, 478 (2019).

22. Wauson E.M., Lorente-Rodriquez A., Cobb M.H.: Mol. Endocrinol. 27, 1188 (2013).

23. Straub S.G., Kornreich B., Oswald R.E., Nemeth E.F, Sharp G.W.: J. Biol. Chem. 275, 18777 (2000).

24. Bowe J.E., Franklin Z.J., Hauge-Evans A.C., King A.J., Persaud S.J., Jones P.M.: J. Endocrinol. 222, G13 (2014).

25. Rybczynska A., Lehmann A., Jurska-Jasko A., Boblewski K., Orlewska C., et al.: J. Endocrinol. 191, 189 (2006).

26. Rybczyńska A., Boblewski K., Lehmann A., Orlewska C., Foks H., et al.: Am. J. Hypertens. 18, 364 (2005).

27. Rubin A.A., Roth F.E., Taylor R.M., Rosenkilde H.: J. Pharmacol. Exp. Ther. 136, 344 (1962). 